\title{
UMA ANÁLISE ÉTICO-JURÍDICA DO TRATAMENTO DISPENSADO ÀS DIRETIVAS ANTECIPADAS DE VONTADE E À EUTANÁSIA NO ÂMBITO DO PLS No 149/2018
}

\section{AN ETHICAL-LEGAL ANALYSIS OF THE TREATMENT OF ADVANCE DIRECTIVES OF WILL AND OF EUTHANASIA UNDER BRAZILIAN SENATE BILL N. 149/2018}

Recebimento: 9 set. 2019

Aceitação: 11 set. 2020

Daniel Braga Lourenço

Doutor em Direito

Afiliação institucional: UniFG - Centro Universitário (Guanambi, BA, Brasil)

Lattes iD: http://lattes.cnpq.br/5869787995233483

Email:daniel@lourenco.adv.br

Alex Meira Alves

Mestrando em Direito

Afiliação institucional: UniFG - Centro Universitário (Guanambi, BA, Brasil)

Lattes iD: http://lattes.cnpq.br/5428568510412500

Email: alexmeira.jus@outlook.com

Como citar este artigo / How to cite this article (informe a data atual de acesso / inform the current date of access):

LOURENÇO, Daniel Braga; ALVES, Alex Meira. Uma análise ético-jurídica do tratamento dispensado às diretivas antecipadas de vontade e à eutanásia no âmbito do PLS n ${ }^{\circ}$ 149/2018. Revista da Faculdade de Direito UFPR, Curitiba, v. 66, n. 1, p. 9-29, jan./abr. 2021. ISSN 2236-7284. Disponível em: https://revistas.ufpr.br/direito/article/view/69112. Acesso em: 30 abr. 2021. DOI: http://dx.doi.org/10.5380/rfdufpr.v66i1.69112.

\section{RESUMO}

Esta pesquisa objetiva analisar qual o tratamento dispensado à eutanásia no Projeto de Lei do Senado (PLS) n ${ }^{\circ}$ 149/2018, que regulamenta as diretivas antecipadas de vontade. Entretanto, é dada especial atenção ao testamento vital, por ser um tema que está concatenado de forma intrínseca à eutanásia. Para tanto, são discutidos inicialmente alguns conceitos essenciais, tais como os de eutanásia ativa (direta e indireta) e passiva - aí incluída a ortotanásia, não como sinônimo, mas como um subtipo. Utiliza-se pesquisa bibliográfica e documental, pautando-se, principalmente, a partir do referencial teórico proposto por Peter Singer (2018) e confrontando-o com a perspectiva de outros autores. Foi possível observar que não há razões para se distinguir juridicamente as diversas modalidades de eutanásia ativa e a ortotanásia, como faz o projeto. O PLS nº 149/2018, na verdade, apenas replica o disposto nas Resoluções $n^{\circ}$ 1.805/2006 e n ${ }^{\circ}$ 1.995/2012, do Conselho Federal de Medicina, é genérico e não aprofunda a regulamentação das diversas formas de eutanásia. Com isso, dá-se continuidade ao modelo paternalista na relação médico-paciente, com prejuízos evidentes à autonomia e aos direitos da personalidade do paciente. 


\title{
PALAVRAS-CHAVE
}

Eutanásia. Ortotanásia. Diretivas antecipadas de vontade. Autonomia.

\begin{abstract}
This research aims at analyzing the treatment of euthanasia in the Senate Bill (PLS for its Portuguese initials) n. 149/2018, which regulates the advance directives of will. However, special attention is given to the living will, considering it is intrinsically linked to euthanasia. For this, some essential concepts such as active (direct and indirect) and passive euthanasia (including orthotanasia, not as a synonym, but as a subtype) are initially addressed, all through a bibliographical and documentary research, based mainly on the theoretical framework proposed by Peter Singer (2018) which is confronted with perspectives of other authors. It was possible to observe that there are no reasons to distinguish legally the various modalities of active euthanasia and orthotanasia, as the project does. The PLS n. 149/2018, in fact, only replicates the provisions of Resolutions n. 1805/2006 and n. 1995/2012 of the Brazilian Federal Council of Medicine, is generic and does not deepen the regulation of the various forms of euthanasia. This gives continuity to the paternalistic model in the doctorpatient relationship, with evident damages to the autonomy and to the personality rights of the latter.
\end{abstract}

\section{KEYWORDS}

Euthanasia. Orthotanasia. Advance directives of will. Autonomy.

\section{INTRODUÇÃO}

Com a crescente modernização da tecnologia nos campos da biologia e da medicina os meios de manutenção da vida se ampliaram significativamente. Embora a técnica tenha avançado rapidamente, pretende-se demonstrar, neste trabalho, que ainda predomina na cultura médica uma postura predominantemente paternalista no âmbito da relação médico-paciente.

No Brasil, especialmente após a promulgação da Constituição de 1988, começou a se debater com mais frequência sobre esse fenômeno, principalmente tendo em vista a alta carga axiológica conferida ao valor da autonomia individual e da dignidade existencial humana, expressamente garantidos pelo texto constitucional como principais vetores interpretativos de todo o ordenamento jurídico pátrio (BRASIL, 1988).

É nesse panorama que é introduzida a importante questão da eutanásia e de suas diversas possibilidades e classificações, já que esse procedimento estaria destinado a garantir uma morte digna ao paciente em estado de comprovada terminalidade, em situação de doença incurável ou cujos tratamentos sejam demasiadamente invasivos e possam provocar sofrimento excessivo e injustificável.

Para os fins de delimitação de análise e recorte conceitual deste trabalho foram analisados apenas os conceitos de eutanásia ativa - nas suas modalidades direta e indireta -, eutanásia passiva e a distinção existente entre esta e a ortotanásia. A partir daí, discutir-se-á o Projeto de Lei do Senado 
(PLS) n ${ }^{\circ}$ 149/2018, com referência às inovações trazidas pelo projeto e sobre quais as espécies de eutanásia ele legitima ao tratar das diretivas antecipadas de vontade ${ }^{1}$, especialmente quando trata do denominado "testamento vital”.

Para tanto, utilizou-se como referencial teórico o filósofo australiano Peter Singer, primordialmente a partir de sua obra "Ética Prática” (2018). Singer é um dos filósofos mais influentes do século XX. Trabalha no âmbito das posições consequencialistas (é um utilitarista preferencial) e centra sua análise da Ética Aplicada a partir da necessidade de modificar o comportamento humano em relação a variados temas polêmicos, tais como a relação homem-animal, os dilemas morais associados ao início e fim da vida humana e ao dever de assistência às pessoas em estado de vulnerabilidade e necessidade (altruísmo eficaz). Uma grande característica da obra de Singer, apontada por Jamieson (2000), é a de que, para Singer, a verificação acurada dos fatos importa e as ações individuais podem fazer diferença no que se refere à maximização agregada da felicidade no mundo.

A partir dessa análise crítica, incidente sobre os termos propostos pelo PLS n. 149/2018, conclui-se que não há motivos robustos para diferenciar juridicamente os diversos procedimentos de eutanásia ativa e passiva, especialmente aqueles relativos à subespécie denominada de ortotanásia, desde que obedecidos alguns pressupostos fundamentais, tal como já prescreve o projeto legislativo em comento. O referido projeto não traz inovações no tratamento da matéria - especialmente quando comparado ao estado atual da doutrina e aos próprios atos normativos provenientes do Conselho Federal de Medicina -, apresentando-se de maneira geral como inadequado e insuficiente para resolver os problemas e dilemas presentes no tema.

\section{EM BUSCA DA CONCEITUAÇÃO DA EUTANÁSIA}

A complexidade dos debates envolvendo o tema da "morte com dignidade” justificam sua escolha como objeto de análise deste trabalho, especialmente diante da recente proposição do mencionado PLS nº 149/2018. Os valores da dignidade existencial humana, da liberdade, da proteção da vida e da autonomia muitas vezes entram em conflito suscitando dilemas morais e jurídicos

1 Ao tratar da origem do instituto das diretivas antecipadas de vontade na Califórnia, Dadalto (2018) explica que esse na verdade é um gênero, do qual são espécies o testamento vital e o mandato duradouro. Ainda, segundo Cavalheiro (2016), “O testamento vital permite a documentação da vontade expressa para aquele paciente que deseja garantir a suspensão de procedimentos como reanimação ou cirurgia. O documento também pode ser utilizado para assegurar que essas intervenções sejam colocadas em prática”. Quanto ao mandato duradouro, ele vai servir "para o paciente que pretende nomear um procurador para tomar decisões em caso de doença terminal” (CAVALHEIRO, 2016), funcionando como uma procuração para tratar de assuntos relacionados à saúde do outorgante. 
atinentes à possibilidade de disposição do próprio corpo e da vida diante de doenças terminais incuráveis que podem vir, concomitantemente, a causar intenso sofrimento e perda significativa do bem-estar experimental.

Embora o conceito de eutanásia seja amplamente debatido, a palavra, de etimologia grega (eu: boa; thanos: morte), conforme elucida Singer (2018, p. 239), é utilizada "para se referir à morte deliberada daqueles que têm doenças incuráveis e sofrem de angústia e dores insuportáveis, com o propósito de poupá-los de mais aflição e sofrimento”. Nesse sentido, tal definição usual de eutanásia traz em si, implícita, a noção de que qualidade de vida seria em princípio mais relevante do que quantidade de vida.

Entretanto, para fins de delimitação do procedimento legislativo, algumas questões devem ser analisadas mais detidamente: (a) quem estaria habilitado a dar esse parecer conclusivo sobre a situação da doença e da suposta não reversibilidade do quadro clínico apresentado pelo paciente? (b) qualquer pessoa estaria autorizada a verificar se uma dada enfermidade não tem cura ou tratamento? (c) haveria necessidade de um laudo de uma junta médica especializada?

O padrão mínimo de regularidade/legalidade da prática exigiria, de modo inafastável, que ao menos um profissional habilitado (um médico, de preferência especializado na doença que acomete o paciente) emitisse um parecer fundamentado sobre o diagnóstico, bem como o quadro atual detalhado do paciente e possíveis alternativas e perspectivas de tratamento da doença e possíveis desdobramentos. Descarta-se, desse modo, a possibilidade de realização de eutanásia nas hipóteses de ausência de parecer técnico sobre o atual quadro de saúde do paciente e de sua evolução.

Ultrapassando-se a fase de diagnóstico e análise de possíveis alternativas de tratamento, há debate acerca de quem estaria autorizado a realizar ou deixar de realizar o procedimento destinado a tirar a vida da pessoa doente. Situações em que pessoas sem formação médica (e.g. familiares) realizassem o conjunto de atos destinados a tal finalidade poderiam ser consideradas como eutanásia ou seriam, na verdade, modalidade de "homicídio piedoso"2? Nessa hipótese não haveria uma abertura perigosa para o erro de avaliação técnica sobre o real estado de saúde do paciente?

A respeito deste tema Iberê Anselmo Garcia faz as seguintes considerações:

\begin{abstract}
Deve-se reservar o termo eutanásia para as práticas juridicamente reguladas dos profissionais de saúde no tratamento de doentes graves em estado terminal ou vítimas de grandes limitações e sofrimentos físicos. A morte causada por misericórdia ou piedade por leigo deveria ser denominada homicídio piedoso. Essa diferenciação baseia-se no fato de que são diversos os motivos que levam os médicos, de um lado, e os leigos, de outro, a praticarem estas condutas e ao fato de que só é possível regulamentar essa prática em ambientes tecnicamente controlados (GARCIA, 2007, p. 272).
\end{abstract}

2 Expressão utilizada por Garcia (2007, p. 272) para definir os casos de eutanásia praticados por leigos. 
Da definição apresentada por Singer (2018), é possível extrair uma outra condição essencial para a prática da eutanásia: a pessoa a ser submetida ao procedimento deve possuir uma doença incurável/terminal e sofrer de angústia e dores insuportáveis (quadro de deterioração relevante, continuada e permanente do bem-estar experimental do indivíduo).

Essa posição de Singer está intimamente conectada à sua opção teórica pelo utilitarismo preferencial. Em síntese, de acordo com essa posição, as pessoas são moralmente obrigadas a calcular os custos e benefícios de suas condutas, com o objetivo final de maximizar as preferências/interesses fundamentais de todos os atingidos pela conduta em questão. Esse cálculo está pautado na imparcialidade (um interesse legítimo deve ser protegido a despeito de quem o possua) e na igual consideração de interesses (interesses semelhantes devem, em princípio, contar de forma semelhante). O prolongamento artificial da vida pode, nessas situações, atentar contra a dignidade e os interesses do paciente, gerando uma situação de maior sofrimento que benefício para todos os envolvidos.

A própria caracterização da condição de terminalidade (impossibilidade de cura da condição que aflige o paciente) pode, todavia, ser questionada. Naqueles casos em que a doença tiver cura, mas essa cura implicar um sofrimento físico ou psicológico prolongados e agudos, poder-se-ia autorizar a eutanásia?

A esse respeito, há de se destacar uma decisão do Tribunal de Justiça do Rio Grande do Sul, na Apelação Cível nº 70054988266, que negou a realização de cirurgia mutilatória em paciente com pé necrosado (RIO GRANDE DO SUL, 2013), chegando a se afirmar no julgado que isso representaria uma situação de ortotanásia ou paraeutanásia (ajuda dada pelo médico ao processo natural que culmina com a morte do paciente) - tida para Singer (2018), nesse caso, como uma eutanásia passiva, já que o autor, conforme se verá, não faz essa diferenciação:

DIREITO À VIDA - Ortotanásia - Idoso portador de doença grave e com risco de morte que se nega a receber tratamento médico - Admissibilidade de Manifestação de vontade de não prolongar a vida além do processo natural que coaduna o direito à vida e o princípio da dignidade da pessoa - Carta Magna, ademais, que institui o direito e não o dever de viver. 1. Se o paciente, com o pé esquerdo necrosado, se nega à amputação, preferindo, conforme laudo psicológico, morrer para "aliviar o sofrimento"; e, conforme laudo psiquiátrico, se encontra em pleno gozo das faculdades mentais, o Estado não pode invadir seu corpo e realizar a cirurgia mutilatória contra a sua vontade, mesmo que seja pelo motivo nobre de salvar sua vida.

2. O caso se insere no denominado biodireito, na dimensão da ortotanásia, que vem a ser a morte no seu devido tempo, sem prolongar a vida por meios artificiais, ou além do que seria o processo natural.

3. O direito à vida garantido no art. $5^{\circ}$, caput, deve ser combinado com o princípio da dignidade da pessoa, previsto no art. $2^{\circ}$, III, ambos da CF, isto é, vida com dignidade ou razoável qualidade. A Constituição institui o direito à vida, não o dever à vida, razão pela qual não se admite que o paciente seja obrigado a se submeter a tratamento ou cirurgia, máxime quando mutilatória. Ademais, na esfera infraconstitucional, o fato de o art. 15 do CC 
proibir tratamento médico ou intervenção cirúrgica quando há risco de vida, não quer dizer que, não havendo risco, ou mesmo quando para salvar a vida, a pessoa pode ser constrangida a tal.

4. Nas circunstâncias, a fim de preservar o médico de eventual acusação de terceiros, tem-se que o paciente, pelo quanto consta nos autos, fez o denominado testamento vital, que figura na Res. CFM 1995/2012.

5. Apelação desprovida (RIO GRANDE DO SUL, 2013).

Segundo a regra da decisão contida no julgado supramencionado, a aplicação da eutanásia não estaria restrita a situações de doenças incuráveis, mas ao risco e às características do tratamento. Cite-se, por exemplo, tratamentos mais invasivos e com um dano ou sofrimento posterior relevante, seja ele de ordem física ou psicológica. Vale destacar a esse respeito que o Conselho Federal de Medicina editou a Resolução $n^{\circ}$ 1.805/2006, que passou a aprovar o procedimento da ortotanásia em paciente terminal ou incurável, com base no art. $5^{\circ}$, III, da Constituição Federal, que veda a submissão a tortura e a tratamento desumano ou degradante.

Na ortotanásia o médico não age (não adota comportamento comissivo), apenas deixa de prolongar, artificialmente, uma vida com alto grau de sofrimento e sem expectativa de recuperação. Nesse sentido, é conveniente também lembrar a isenção de pena prevista para a prática da ortotanásia, constante no art. 121, § $4^{\circ}$, do Esboço do Anteprojeto da Parte Especial do Código Penal (isenção de pena para o médico que, com o consentimento do paciente ou de seu representante legal, suprime ou deixa de aplicar terapia destinada a prolongar artificialmente vida em quadros irreversíveis).

Ressalte-se, portanto, a necessidade de uma conceituação clara a respeito do tema a fim de pautar a atuação mais eficiente do legislador. Diante das considerações apresentadas, propõe-se o seguinte conceito de eutanásia: morte deliberada com fins humanitários ${ }^{3}$, praticada com o acompanhamento de profissional habilitado e com o consentimento do paciente ${ }^{4}$ ou seu representante constituído, em situações de enfermidades, devidamente reconhecidas, que importem em sofrimento excessivo e que não haja possibilidade de cura ou que esta implique tratamentos invasivos, extraordinários, sem resultados efetivos ou desproporcionais.

3 Se não tiver um fim humanitário, pode-se classificar como uma espécie de extermínio/homicídio ou genocídio a depender da motivação e da quantidade de vítimas envolvidas.

4 A ausência do consentimento caracterizaria um homicídio e não uma eutanásia. Singer (2018) classifica tal tipo de procedimento como eutanásia involuntária. 


\section{DIFERENÇAS ENTRE EUTANÁSIA ATIVA, PASSIVA E ORTOTANÁSIA}

Para fins do estudo ora proposto, convém elucidar, ainda que sinteticamente, os conceitos de eutanásia ativa, passiva e ortotanásia, ressaltando eventuais diferenças morais entre elas e quais as justificativas para sua permissão ou proibição, sem pretensões de exaurir a temática.

Singer (2018) entende por eutanásia passiva a conduta de "permitir a morte” ou "deixar morrer”, estando configurada mediante uma omissão, não mencionando a ortotanásia como modalidade distinta da eutanásia passiva. Por sua vez, para ele, a eutanásia ativa exigiria uma ação de um agente com vistas a causar o resultado morte a terceiro em estado de terminalidade.

Ademais, quanto à eutanásia ativa, Sameshima (2012) esclarece que a doutrina a tem dividido em duas modalidades, conforme a intenção do agente. São elas: eutanásia ativa direta (com intenção clara de causar a morte, como nos casos de interrupção dos suportes artificiais de manutenção da vida, aplicação de injeção letal ou em situações em que são ministradas substâncias capazes de conduzir à morte) e indireta ou de duplo efeito (a morte aqui pode ser um resultado da utilização de um tratamento paliativo, tendo como possibilidade de efeito adverso a morte. A intenção do agente é aliviar o sofrimento, mas assume objetivamente com isto o risco de causar a morte).

Alguns autores, no entanto, consideram não existir diferença moral ao comparar a eutanásia passiva e a ativa. Para esses autores, não haveria uma distinção significativa ou moralmente relevante entre matar ou deixar morrer.

James Rachels (1975) postula essa equivalência e, para ilustrar seu ponto, traz o exemplo de duas pessoas envolvidas no afogamento de uma criança. A primeira pessoa, Smith, afoga seu sobrinho de seis anos de idade numa banheira a fim de herdar sua fortuna. Jones, movido pela mesma finalidade, deixa seu sobrinho de seis anos se afogar numa banheira depois de ter escorregado e batido a cabeça. Para Rachels (1975) os casos são idênticos na motivação e nos resultados. A única distinção entre eles é a de que Smith matou seu sobrinho, enquanto Jones deixou que ele morresse. Logo, segundo tal autor, não haveria diferença moral relevante entre os dois casos (RACHELS, 1975).

Em igual sentido, Singer destaca essa posição de equivalência entre as práticas de matar e deixar morrer:

A reflexão sobre esses casos leva-nos à conclusão de que não existe nenhuma diferença moral intrínseca entre matar e deixar morrer. Ou seja, não existe diferença que dependa exclusivamente da distinção entre um ato e uma omissão (não significa que todos os casos nos quais se permite que alguém morra sejam moralmente equivalentes a tirar a vida. Outros fatores - extrínsecos - serão, às vezes, relevantes...). Permitir que alguém morra - o que às vezes se chama de "eutanásia passiva" - já é aceito como um procedimento humanitário e apropriado em certos casos. Se não existe nenhuma diferença moral intrínseca entre matar 
alguém e permitir que alguém morra, a eutanásia ativa também deveria ser aceita como humanitária e apropriada em determinadas circunstâncias (SINGER, 2018, p. 276).

A eutanásia passiva pode eventualmente ser mais danosa em alguns casos, pois os pacientes chegam a demorar semanas ou meses até a ocorrência efetiva da morte quando, por exemplo, não são oferecidos os mecanismos de manutenção artificial da vida (sistemas de hidratação e nutrição) (SINGER, 2018).

Entretanto, tudo indica que o referido autor não levou em consideração pesquisas mais recentes que sustentam que, em muitos casos, a suspensão dos sistemas de nutrição e hidratação não surte efeito e é considerada como tratamento extraordinário. Nesse sentido, é oportuno citar aqui os estudos realizados por Luciana Dadalto e Carla Vasconcelos Carvalho (2016), que apontam uma contradição entre a práxis e as pesquisas até então desenvolvidas. Segundo elas, "a dificuldade em limitar a nutrição e hidratação nos pacientes em fim de vida está na dificuldade de aceitar que a verdade é que o paciente não morrerá de fome e sede, mas sim que ele não sente fome e sede porque está morrendo” (DADALTO; CARVALHO, 2016, p. 41).

Contudo, Dadalto e Carvalho (2016) ressaltam que não é possível prever com segurança, em todas as hipóteses, que não haverá sofrimento, devendo-se analisar caso a caso, a exemplo dos estudos dos pacientes em estado vegetativo em que o fornecimento de suporte artificial de nutrição e hidratação (AHA) pode ser considerado cuidado básico e não extraordinário. De acordo com as autoras:

Em situações limítrofes como a do fim da vida as generalizações devem ser evitadas, de modo que o profissional e o pesquisador devem sempre se ater às especificidades do caso concreto para determinar se a suspensão de AHA deverá ser recomendada, como prática de ortotanásia, uma vez que a AHA para o paciente em questão funciona como tratamento extraordinário, ou se a AHA deve ser mantida, por se tratar, no caso específico, de um cuidado paliativo (DADALTO; CARVALHO, 2016, p. 43).

Outro ponto que merece destaque é o fato de que a eutanásia passiva, por si só, pode não importar em mais sofrimento quando é acompanhada de cuidados paliativos. Não é à toa que há autores que, conforme será demonstrado a seguir, fazem essa diferenciação entre a eutanásia passiva pura e aquela em que há alguma forma de intervenção para evitar ou amenizar o sofrimento com terapias e cuidados paliativos, sendo esta última denominada comumente de ortotanásia. Ou seja, na ortotanásia, o paciente não é simplesmente abandonado à própria sorte.

Para Cauduro (2007, p. 21), “a eutanásia passiva ou indireta consistiria na morte do paciente dentro de uma situação de terminalidade, em virtude da omissão médica”. Ocorre que a autora trata como sinônimas a eutanásia passiva e a ortotanásia, ao mesmo tempo que considera a ação de desligar 
os aparelhos de suporte vital como uma forma de eutanásia passiva ${ }^{5}$ - o que, em certo sentido, contraria o seu próprio conceito. Parece claro que o ato de desligar os aparelhos de suporte vital é uma conduta comissiva, não havendo que se falar em omissão nesse caso. Como se percebe, é comum haver verdadeira confusão entre os conceitos de eutanásia ativa, passiva e ortotanásia.

Varalli, contudo, tentando esclarecer esse ponto, conceitua a ortotanásia como:

[...] deixar a morte ocorrer naturalmente, sem qualquer interferência para atrasar ou adiantar o processo. Nos casos em que o processo natural da morte já esteja ocorrendo, o médico apenas contribui para que este estado siga seu curso natural, atuando para aliviar as dores do paciente. É uma conduta médica restritiva, que visa prover conforto ao paciente, sem interferir no momento da morte. Todos os tratamentos deixam de ser realizados e são praticados apenas os cuidados paliativos (VARALLI, 2017, p. 32).

Sendo assim, o conceito que se apresenta de forma mais clara e gera menos confusões, é aquele segundo o qual se entende a eutanásia passiva como uma conduta omissiva destinada a causar a morte do paciente cujo óbito é iminente, ao passo que, na ortotanásia, apesar dessa omissão, os cuidados paliativos não deixam de ser prestados. Desse modo, a ortotanásia poderia ser considerada um subtipo/subespécie de eutanásia passiva.

Diante do exposto, a eutanásia passiva pura parece não ser justificável, tendo em vista que importa em sofrimento desnecessário, afrontando, consequentemente, a dignidade do indivíduo e o princípio da beneficência que orienta a bioética. A ortotanásia, por sua vez, demostra ser um procedimento mais humanitário em relação à primeira, já que são mantidos os cuidados paliativos mínimos necessários. Por fim, há de se considerar que a eutanásia ativa pode representar uma modalidade em que há menor quantidade de sofrimento envolvido, sendo necessário aprofundar os estudos sobre quais motivações levam à sua proibição. Isso porque se essas motivações estiverem pautadas numa concepção puramente religiosa acerca da santidade da vida humana ${ }^{6}$, não seria

5 Cauduro (2007, p. 80) afirma que: “o ato de desligar os aparelhos é conhecido como eutanásia passiva ou ortotanásia e, não deveria caracterizar crime algum, uma vez que está se respeitando o momento natural da morte [...]”.

6 Destaque-se, nesse sentido, as considerações de Carmela Marcuzzo do Canto Cavalheiro (2016), para quem “O debate sobre a eutanásia em âmbito nacional ainda encontra forte respaldo religioso, sendo o tema morte considerado tabu por parte da sociedade civil. Para os oponentes da eutanásia, a vida seria sagrada e, por esta razão, haveria a impossibilidade de intervenção humana sobre este bem maior. De acordo com esta corrente, discutir a eutanásia seria inviável, pois o fim da vida só deve ser determinado por Deus. Para este argumento não há como debater procedimentos de eutanásia ou suicídio assistido, tendo em vista a impossibilidade de controle sobre algo inerente a uma força maior”. Como prova dessa influência da religião, pode-se citar ainda a decisão do Tribunal de Justiça do Rio Grande do Sul na Apelação Cível No 70054988266, que deixou evidente na fundamentação do acórdão que: “O caso sub judice se insere na dimensão da ortotanásia. Em suma, se o paciente se recusa ao ato cirúrgico mutilatório, o Estado não pode invadir essa esfera e procedê-lo contra a sua vontade, mesmo que o seja com o objetivo nobre de salvar sua vida. Com efeito, o Papa João Paulo II, ao promulgar, em 1995, a Encíclica Evangelium Vitae, condenou apenas a eutanásia e a distanásia, silenciando quanto à ortotanásia. Isso é interpretado como implícita a sua admissão pela Igreja Católica, que é, como sabemos, bastante ortodoxa nos temas relativos à defesa da vida” (RIO GRANDE DO SUL, 2013). 
possível impor ao indivíduo que deseja realizar o procedimento, numa sociedade plural e laica, a assimilação interna desse ideal ${ }^{7}$.

\section{A REGULAMENTAÇÃO DA EUTANÁSIA NO BRASIL}

No Brasil não há uma regulamentação específica, direta, incidente sobre a prática da eutanásia, seja no âmbito do direito civil, seja no do direito penal. Tal situação gera apenas incerteza e insegurança nas relações entre médico e paciente, reforçando usualmente uma postura paternalista dos profissionais da saúde, com desprezo à autonomia do paciente.

Nesse sentido, ao criticar a falta de regulamentação da eutanásia e da ortotanásia no Código Penal, Diego Ferreira de Oliveira (2016, p. 78) aponta que parte da doutrina passou a considerar “a eutanásia e a ortotanásia como atos tipificados como homicídio, na primeira hipótese na modalidade comissiva e, na segunda, na omissiva”.

Ainda, segundo Oliveira (2016), essa deficiência na tipificação legal e a incerteza jurisprudencial leva os profissionais da saúde a adotarem uma postura paternalista em desrespeito à autonomia do paciente. Com isso, consequentemente, corrobora-se a prática da distanásia, ao invés da eutanásia.

O paternalismo, segundo Gerald Dworkin (2020, p. 1, tradução nossa), pode ser conceituado como “a interferência do Estado ou de um indivíduo sobre outra pessoa, contra a sua vontade, defendida ou motivada pela alegação de que esse indivíduo estará em melhor situação ou protegido de danos”.

Em contrapartida ao posicionamento paternalista, há o movimento de tradição liberal, que, em termos gerais, preza a soberania e autonomia do indivíduo na tomada de decisões, desde que não cause prejuízos a terceiros ${ }^{8}$. Como expoente dessa corrente pode-se destacar o filósofo John Stuart Mill, com especial destaque para sua obra On liberty, publicada em 1859.

7 Sanches (2014) salienta que “como direito fundamental que é, o direito da personalidade, manifestado, na hipótese que ora interessa, através do direito da dignidade da pessoa humana, constitui verdadeiro direito de defesa e visa a manter ou proteger as mais variadas posições subjetivas do cidadão não apenas em face da coletividade mas também contra o próprio Poder Público, seja pelo não impedimento da prática de determinado ato, seja pela não intervenção em situações subjetivas ou pela não eliminação de posições jurídicas”. Trilhando esse mesmo raciocínio, Oliveira (2016, p. 43) afirma que “O Estado deve sempre nortear suas ações pela proteção das liberdades individuais frente às pressões advindas de escolhas coletivas, quando estão em jogo as escolhas mais íntimas definidoras de sua própria personalidade, naquilo que diz respeito as [sic] suas próprias vidas, como são as questões afetas à morte digna ora em análise.”

8 Ruth Faden, Justin Bernstein e Sirine Shebaya (2020), a respeito do princípio da lesividade (harm principle), proposto por Mill em On liberty - mesmo que não o tenha feito de forma expressa -, informam que tal axioma tem sido interpretado no sentido de que "a única justificativa para interferir na liberdade de um indivíduo, contra sua vontade, 
Nesse panorama, a autonomia moral do indivíduo atua como uma barreira ao paternalismo, fazendo prevalecer a ideia de autogoverno (self-rule ou self-government). Conforme assinala John Christman (2020, p. 2, tradução nossa), "ser autônomo é governar a si mesmo, ser dirigido por considerações, desejos, condições e características que não são simplesmente impostas externamente a alguém, mas são parte do que pode, de alguma forma, ser considerado o eu autêntico”.

Na linha dessa tradição liberal, Freitas e Baez (2014) ressaltam que nos últimos anos a autonomia passou a ser concebida mediante duas perspectivas: autonomia como o direito de ser deixado em paz (não interferência) e como autonomia decisória. Sendo assim, salientam que hoje há uma tendência ao abandono dessa postura paternalista, priorizando-se a aplicação da doutrina do consentimento livre e informado ${ }^{9}$, de modo a prevalecer a noção de autodeterminação. Como marco dessa mudança de paradigma, tais autores apontam que “esse movimento já é visível a partir do Relatório Belmont de 1978, apresentado pela National Comission for the Protection of Human Subjects of Biomedicals and a Behaviors Research, instituída pelo governo americano em 1974” (FREITAS; BAEZ, 2014, p. 260).

Levando em conta esse movimento da doutrina do consentimento livre e informado, o Conselho Federal de Medicina (CFM) editou duas resoluções no sentido de tentar regulamentar a conduta ética do médico em casos em que o paciente se manifestou de forma livre e consciente sobre o seu desejo de ser (ou não) submetido a determinados tratamentos médicos.

Nesse sentido, há de se destacar a Resolução nº 1.805/2006 ("Na fase terminal de enfermidades graves e incuráveis é permitido ao médico limitar ou suspender procedimentos e tratamentos que prolonguem a vida do doente, garantindo-lhe os cuidados necessários para aliviar os sintomas que levam ao sofrimento, na perspectiva de uma assistência integral, respeitada a vontade do paciente ou de seu representante legal”) e a n 1.995/2012 (“Dispõe sobre as diretivas antecipadas de vontade dos pacientes) ${ }^{10}$, ambas do Conselho Federal de Medicina, que reforçam o dever do médico de respeitar a vontade e a autonomia do paciente (CONSELHO FEDERAL DE MEDICINA,

é para prevenir danos diretos e não consensuais a terceiros” (FADEN, BERNSTEIN, SHEBAYA, 2020, p. 27, tradução nossa).

9 Sobre a doutrina do consentimento livre e informado, Cauduro (2007, p. 81) diz que "O consentimento informado, termo utilizado pela primeira vez em 1767, pode ser fundamentado pelo princípio básico do respeito pela pessoa nos seus valores fundamentais. $\mathrm{O}$ consentimento sob o aspecto jurídico pode comprovar a declaração de vontade emitida pelo paciente, com objetivo de constituir prova em eventual demanda judicial”. Todavia, para fins penais, tratando-se da eutanásia, esse consentimento não tem o condão de excluir a ilicitude da conduta, conforme considera Garcia (2007). Isso, de certa forma, demonstra a tradição do direito pátrio em negar a autonomia do indivíduo.

10 O Ministério Público Federal moveu Ação Civil Pública, de nº 0001039-86.2013.4.01.3500, em face do Conselho Federal de Medicina, cujo pedido consistia na suspensão da aplicação da Resolução n ${ }^{\circ}$ 1.995/2012/CFM, alegando para tanto sua inconstitucionalidade. Em sede liminar, o pedido foi acolhido. Ainda não há trânsito em julgado, mas a decisão de primeira instância foi no sentido de entender pela constitucionalidade da referida resolução. 
2012), de esclarecê-lo sobre as modalidades terapêuticas, além de prever a possibilidade de "limitar ou suspender" procedimentos que prologuem a vida do paciente em determinadas situações (CONSELHO FEDERAL DE MEDICINA, 2006). O próprio Enunciado n 37, da I Jornada de Direito da Saúde do CNJ, estatui, na mesma linha, que as diretivas ou declarações antecipadas de vontade, que especificam os tratamentos médicos aos quais o declarante deseja ou não se submeter quando incapacitado de se expressar autonomamente, devem ser feitas preferencialmente por escrito, por instrumento particular, com duas testemunhas, ou público, sem prejuízo de outras formas inequívocas de manifestação admitidas em direito (CONSELHO NACIONAL DE JUSTIÇA, 2014).

Contudo, apesar dos avanços que tal regulamentação feita pelo Conselho Federal de Medicina representa, como ressaltado acima, o tema ainda é controverso devido ao receio de responsabilização cível e criminal dos profissionais de saúde, em especial dos médicos. O principal receio se dá em decorrência da ausência de legislação (lei em sentido estrito) sobre o tema. Sendo assim, apresenta-se relevante a análise dos eventuais projetos de lei que tratam da matéria, notadamente os relacionados à regulamentação da eutanásia e do testamento vital, já que são temáticas intimamente relacionadas à dignidade existencial, à liberdade da pessoa humana e à humanização na terminalidade da vida.

\section{O TESTAMENTO VITAL E O TRATAMENTO DISPENSADO À EUTANÁSIA NO PLS $\mathrm{N}^{\mathrm{O}}$ 149/2018}

O instituto jurídico relativo às diretivas antecipadas de vontade surgiu formalmente em 1967, a partir dos estudos realizados por Luis Kutner. Pode-se dizer que a expressão diretivas antecipadas de vontade representam um gênero que abarca, respectivamente, o mandato duradouro (transmissão da vontade do paciente, relativa às decisões sobre sua saúde, a um ou mais mandatários que passam a valer no caso de incapacidade do mandante), o testamento vital (documento formal com estipulações do paciente a respeito do tratamento a ser ministrado no caso de estado vegetativo ou terminalidade) e, para alguns, também as diretivas de cuidado médico avançadas (que incorporam em um único documento as determinações oriundas das duas espécies anteriores).

Kutner estabeleceu alguns requisitos para a confecção do testamento vital (living will): (a) o paciente capaz determinaria, por escrito, sua recusa a se submeter a determinados tratamentos quando seu estado de saúde, em situação de extrema gravidade, assim determinasse; (b) a vontade manifestada no âmbito do testamento vital seria hierarquicamente superior à vontade médica, dos familiares e amigos do paciente, e o documento deveria ser assinado por, no mínimo, duas 
testemunhas; $(c)$ esse documento deveria ser entregue diretamente ao médico ou a algum responsável legal do paciente; $(d)$ o documento deveria ser confirmado pelo comitê do hospital em que o paciente estivesse sendo tratado; e (e) poderia ser revogado a qualquer momento antes de o paciente atingir a inconsciência (DADALTO, 2015, p. 26).

A Califórnia foi o primeiro estado norte-americano a enfrentar a temática do testamento vital, tendo criado o Natural Death Act em 1975, seguido pela legislação federal em 1991 - o The Patient Self-Determination Act (PSDA).

No Brasil, embora ainda não haja legislação específica regendo a matéria, existem alguns projetos de lei relacionados ao assunto. A esse respeito, em primeiro lugar, cabe mencionar que o anteprojeto do novo Código Penal brasileiro (PLS n 236/2012) modifica significativamente a Parte Especial do Código Penal atual, para tratar, no art. 122, da eutanásia e da ortotanásia, com a seguinte redação:

Art. 122. Matar, por piedade ou compaixão, paciente em estado terminal, imputável e maior, a seu pedido, para abreviar-lhe sofrimento físico insuportável em razão de doença grave: Pena - prisão, de dois a quatro anos.

$\S 1^{\circ} \mathrm{O}$ juiz deixará de aplicar a pena avaliando as circunstâncias do caso, bem como a relação de parentesco ou estreitos laços de afeição do agente com a vítima.

$\S 2^{\circ}$ Não há crime quando o agente deixa de fazer uso de meios artificiais para manter a vida do paciente em caso de doença grave irreversível, e desde que essa circunstância esteja previamente atestada por dois médicos e haja consentimento do paciente, ou, na sua impossibilidade, de ascendente, descendente, cônjuge, companheiro ou irmão (BRASIL, 2012, p. 46).

Apesar da tipicidade da conduta, a sanção penal passaria a ser considerada menos gravosa, assim como o parágrafo primeiro traria o perdão judicial ao agente que praticar tal tipo penal, inovando-se em relação à legislação penal em vigor ${ }^{11}$.

Outra proposta tendente a alterar a legislação penal, incidente apenas no caso da prática da ortotanásia, é a constante no Projeto de Lei nº 6.715/2009, originado no Senado Federal. Seu objetivo central é excluir a ilicitude da prática da ortotanásia, inserindo um novo artigo no Código Penal brasileiro, que passaria a estabelecer que:

Art. 136-A. Não constitui crime, no âmbito dos cuidados paliativos aplicados a paciente terminal, deixar de fazer uso de meios desproporcionais e extraordinários, em situação de morte iminente e inevitável, desde que haja consentimento do paciente ou, em sua impossibilidade, do cônjuge, companheiro, ascendente, descendente ou irmão.

$\S 1^{\circ}$ A situação de morte iminente e inevitável deve ser previamente atestada por 2 (dois) médicos.

$\S 2^{\circ}$ A exclusão de ilicitude prevista neste artigo não se aplica em caso de omissão de uso dos meios terapêuticos ordinários e proporcionais devidos a paciente terminal (BRASIL, 2009, p. 2).

11 No caso, o Decreto-lei n ${ }^{\circ}$ 2.848, de 7 de dezembro de 1940 (BRASIL, 1940). 
Em razão da falta de previsão legal específica sobre a temática no ordenamento jurídico brasileiro (os arts. 13 e 15 do Código Civil restringem a autonomia da vontade e a liberdade do paciente de maneira excessivamente aberta e indeterminada), foi proposto Projeto de Lei do Senado, de ${ }^{0}$ 149, em 03/04/2018, pelo senador Lasier Martins, tendo como objetivo regulamentar as diretivas antecipadas de vontade e tratar de limites para sua elaboração, bem como de direitos e deveres de médicos e pacientes (BRASIL, 2018).

O PLS n ${ }^{0}$ 149/2018 ainda está em tramitação no Senado, e não se pretende discutir neste estudo todos os seus dispositivos. Serão analisadas apenas as questões relativas ao testamento vital e os dispositivos atinentes às espécies de eutanásia que o projeto regulamenta, seguindo-se os conceitos aqui apresentados. Portanto, para os fins deste trabalho serão verificadas, com centralidade, as disposições constantes dos arts. $2^{\circ}$ e $3^{\circ}$, do PLS n ${ }^{\circ} 149 / 2018$, exceto as do $\S 3^{\circ}$ do art. $3^{\circ}$, cujo tema envolve diretamente a prática do aborto.

O art. $2^{\circ}$ do PLS n ${ }^{\circ}$ 149/2018 traz conceitos básicos, tais como os de: diretivas antecipadas de vontade; representante; pessoa em fase terminal de doença ou acometida de grave e irreversível dano à saúde; cuidados paliativos e procedimentos desproporcionais, fúteis ou extraordinários. Quanto aos conceitos apresentados, quatro merecem destaque - os constantes dos incisos I, III, IV e V, por estarem relacionados às hipóteses em que seria cabível a eutanásia:

\begin{abstract}
Art. $2^{\circ}[\ldots]$
I - diretivas antecipadas de vontade: manifestação documentada por "escritura pública sem conteúdo financeiro" da vontade da pessoa declarante quanto a receber ou não receber determinados cuidados ou tratamentos médicos, a ser respeitada quando ela não puder expressar, livre e autonomamente, a sua vontade; [...]

III - pessoa em fase terminal de doença ou acometida de grave e irreversível dano à saúde: pessoa em estágio avançado de doença incurável e progressiva ou vítima de grave e irreversível dano à saúde, cujo prognóstico, em ambos os casos, seja de morte iminente e para a qual, de acordo com a melhor evidência científica, não exista perspectiva de melhora do quadro clínico mediante a instituição de procedimentos terapêuticos;

IV - cuidados paliativos: procedimentos indispensáveis para promover a qualidade de vida e a dignidade do paciente, mediante prevenção e tratamento com finalidade de alívio de dor e de sofrimento de natureza física, psíquica, social e espiritual;

$\mathrm{V}$ - procedimentos desproporcionais, fúteis ou extraordinários: procedimentos terapêuticos que, no caso concreto do paciente, não são capazes de promover melhor qualidade de vida e cujas técnicas podem impor sofrimentos em desproporção com os possíveis benefícios delas decorrentes (BRASIL, 2018, p. 2-3).
\end{abstract}

Apesar de não prever todas as situações verificáveis nos casos concretos, a apresentação desses conceitos no projeto é relevante, pois serve, ao menos, para auxiliar na delimitação dos casos em que é possível utilizar o procedimento. 
O art. $3^{\circ}$, por sua vez, expressamente estabelece os pressupostos para a declaração antecipada de vontade relacionada a tratamentos médicos:

Art. $3^{\circ}$ Toda pessoa maior e capaz tem o direito de declarar, de forma antecipada, a sua vontade de receber ou não receber determinados tratamentos médicos em época futura, quando se vislumbra estar em condição clínica que se enquadre na situação definida no inciso III do art. $2^{\circ}$ e não puder, em função de sua condição de saúde, expressar autonomamente a sua vontade.

$\S 1^{\circ}$ A declaração especificada no caput, para ser reconhecida pelos profissionais de saúde e pelos serviços de saúde, deverá estar expressa por meio de escritura pública sem conteúdo financeiro, lavrada em Cartório competente.

$\S 2^{\circ}$ Apenas os cuidados ou procedimentos considerados desproporcionais, fúteis ou extraordinários, inclusive hidratação e alimentação artificiais que apenas visem a retardar o processo natural de morte, poderão ser alvo de disposições sobre interrupção de tratamento nas diretivas antecipadas de vontade, vedando-se a recusa a tratamentos paliativos.

$\S 3^{\circ}$ Durante a vigência de gravidez, só poderão ser atendidas as diretivas antecipadas de vontade que não comprometam a vida do nascituro (BRASIL, 2018).

Conforme se observa, não é condição necessária a existência de uma doença incurável para que seja autorizada a eutanásia. Nesse sentido, o projeto deixa evidente que o critério passa a ser o caráter extraordinário ou básico (paliativo) do tratamento. São levados em conta não só os casos de doenças incuráveis como também aqueles em que há pacientes com dano grave à saúde, exigindo-se em ambos os casos a perspectiva de morte iminente. Há, nesse sentido, a intenção explícita do legislador em vedar uma "obstinação terapêutica” destinada a manter a vida a qualquer custo e sob quaisquer circunstâncias.

Quanto à possibilidade de suspensão do suporte artificial de alimentação e hidratação apresentada pelo projeto, há de se destacar as ponderações feitas por Dadalto e Carvalho (2016), que defendem a necessidade de se analisar, caso a caso, se trata-se de um cuidado paliativo - elementar ou básico, nos termos definidos no projeto - ou extraordinário.

Sendo assim, essa dubiedade no que diz respeito ao caráter do tratamento pode gerar incertezas e uma tendência à judicialização dessa questão. No caso, a previsão legal da exigência de um relatório médico testificando o caráter paliativo ou extraordinário do procedimento, devidamente confirmado por um segundo profissional, seria suficiente para dirimir eventuais dúvidas.

Ademais, nota-se que o projeto autoriza não somente a disposição de vontade no sentido de optar pelo não fornecimento (uma omissão), como também a “interrupção” (conduta comissiva) do aprovisionamento de suporte vital, sob a justificativa de prezar uma morte natural. Todavia, em qualquer hipótese, resta vedada a possibilidade de se dispor no testamento vital sobre a renúncia a tratamentos paliativos.

Com isso, nota-se que o projeto veda a eutanásia passiva pura, em que o indivíduo é praticamente abandonado (sem quaisquer cuidados paliativos). Por outro lado, permite a ortotanásia, 
pois, em que pese a omissão referente ao não fornecimento de suporte vital, por exemplo, os cuidados básicos são indispensáveis.

Entretanto, o ponto crucial se refere à possibilidade de realização da eutanásia ativa direta, já que se possibilita a interrupção do fornecimento de suporte artificial, que é concretizada mediante uma ação - o que não é uma novidade, já que a Resolução 1.805/2006 do CFM já permitia ao médico “limitar ou suspender procedimentos” (CONSELHO FEDERAL DE MEDICINA, 2006).

Ocorre que o projeto também deixa espaço para o Conselho Federal de Medicina, por meio de seu Código de Ética, prescrever hipóteses em que não seria cabível a eutanásia. O PLS nº 149/2018 apenas estabelece que o médico pode deixar de cumprir as diretivas antecipadas de vontade quando estas confrontarem com o código de ética da sua profissão (BRASIL, 2018). Além disso, como o art. 41 do referido código de ética veda ao médico abreviar a vida do paciente, mesmo com consentimento dele ou de seu representante (CONSELHO FEDERAL DE MEDICINA, 2010), outras formas de eutanásia ativa direta, exceto a prevista no projeto, tornar-se-iam inviáveis na prática.

Tem-se aqui, portanto, uma incongruência, já que o próprio projeto permite um método que é considerado como eutanásia ativa direta, qual seja, a interrupção de suportes artificiais de manutenção da vida. Assim, nota-se que se criou uma espécie de hierarquização moral dos métodos de eutanásia ativa direta - algo bastante problemático do ponto de vista jurídico e ético -, admitindose apenas uma hipótese, que é a de retirada dos aparelhos de suporte vital.

Levando-se em conta as considerações feitas por Singer (2018), não deveria existir distinção moral ou jurídica entre uma ação de retirar equipamentos de suporte vital e, por exemplo, a aplicação de uma injeção letal. Bastaria que se verificassem as mesmas condições exigidas no projeto, tais como: enfermidade grave ou incurável; iminente risco de morte; a existência apenas de tratamentos extraordinários disponíveis; e o consentimento do paciente. Observados tais requisitos, em ambos os casos ter-se-ia uma ação deliberada do indivíduo, com o mesmo resultado (morte). Só haveria diferença efetiva quanto ao método adotado para atingir essa finalidade.

É nesse sentido que entram em cena as discussões sobre a autonomia do paciente, o direito de autodeterminação sobre o próprio corpo, além dos direitos à privacidade e à identidade pessoal, como ressaltam Freitas e Zilio (2016). Ora, se em ambos os casos a morte se dá mediante um ato comissivo, é salutar que seja garantida ao paciente a escolha de como deseja morrer. Privá-lo dessa opção representaria uma violação a todos esses direitos e valores que integram o rol dos direitos da personalidade.

Dito isso, verifica-se também que o projeto de lei em discussão não abrange os riscos que esses tratamentos paliativos - que não podem ser objeto de renúncia pelos pacientes - podem suscitar, 
já que deixa em aberto a possibilidade de utilização da eutanásia ativa indireta de forma velada. Logo, cabe aqui a advertência de que essa não regulamentação da eutanásia ativa indireta é prejudicial, tendo em vista a possibilidade de eventuais abusos por parte de médicos e demais profissionais de saúde envolvidos direta ou indiretamente no tratamento do paciente $\mathrm{e}^{12}$.

Diante do exposto, verifica-se uma série de lacunas no projeto de lei, havendo a necessidade de uma maior discussão a respeito das espécies de eutanásia que ele, mesmo que de forma implícita, autorizaria. Isso, tendo em vista que o fato de não se querer regulamentar expressamente certos temas apenas suscita mais vazios jurídicos a serem preenchidos pelo Judiciário ${ }^{13}$.

\section{CONSIDERAÇÕES FINAIS}

O tema central do presente artigo consiste na análise do PLS n 149/2018, que trata da figura das diretivas antecipadas de vontade incidentes sobre tratamentos de saúde. Ao analisar o projeto, percebe-se que ele apresenta algumas semelhanças no que se refere ao conceito de eutanásia proposto por Singer (2018), uma vez que não somente as pessoas portadoras de doenças incuráveis poderiam se valer da eutanásia, utilizando-se como critério diferenciador a natureza do procedimento.

Todavia, para se atingir maior segurança jurídica, a lei a ser criada deveria exigir um parecer médico, ratificado por um segundo profissional, atestando-se se, no caso concreto, os tratamentos recomendáveis são extraordinários ou paliativos - até mesmo para evitar eventual judicialização excessiva referente à temática.

Ademais, observa-se que o PLS nº 149/2018 não traz efetivamente nenhuma inovação substancial quando comparado às resoluções do conselho federal de medicina e ao próprio Código de Ética Médica, deixando de discutir, por exemplo, o instituto da eutanásia ativa, tanto na modalidade direta como indireta, que, conforme se sustenta neste trabalho, não possui nenhuma diferença ética ou jurídica relevante em relação ao tratamento dispensado à ortotanásia, considerada aqui não como sinônimo da eutanásia passiva, mas como um subtipo desta - com um incremento: o não desprezo pelos cuidados paliativos.

Ressalte-se ainda que, ao permitir os cuidados paliativos da ortotanásia, que não podem ser objeto de renúncia no testamento vital, abre-se espaço para um uso velado da eutanásia ativa indireta

12 Singer (2018, p. 285), a esse respeito, adverte que: "Na verdade a legalização da eutanásia talvez se convertesse em uma limitação ao poder dos médicos, pois colocaria às claras e sob a fiscalização de outro médico aquilo que alguns desses profissionais já vêm fazendo por iniciativa própria e às escondidas”.

13 Talvez tenha sido essa a razão para a apresentação de um substitutivo ao PLS original, consistente na incorporação do PLS nº 267/2018, de autoria do senador Paulo Rocha, ainda não votado. 
ou de duplo efeito - aquela em que, por exemplo, aplica-se uma certa dosagem do medicamento para se aliviar o sofrimento intenso que aflige o paciente, sendo que essa mesma droga pode levar o paciente à morte. Nesse sentido, desde que observadas as condições previstas no projeto, não há uma clara diferença do aludido procedimento em relação àquele que utiliza, por exemplo, injeção letal, exceto no que diz respeito à intenção do agente $^{14}$.

Novamente, deixar tal tema sem regulamentação expressa apenas fomentará mais dúvidas em relação à responsabilização civil e criminal dos médicos. Se sanar essas incertezas for objetivo do projeto, então ele não terá êxito completo em relação a esse importante aspecto, e, com efeito, a postura paternalista tenderá a se reproduzir, prejudicando, consequentemente, a autonomia e os direitos da personalidade do paciente.

Outro aspecto digno de nota consiste no fato de que o testamento vital se tonaria um instrumento ineficaz, forçando a judicialização de tais relações.

De outro lado, o projeto apenas possibilita a utilização de uma espécie de eutanásia ativa direta, que se trata da suspensão ou interrupção dos suportes artificiais de vida, inclusive de alimentação e hidratação, não havendo motivos éticos ou jurídicos para diferenciação em relação a outros métodos que também se enquadram como eutanásia ativa direta.

O que se nota, conforme apontado por Cavalheiro (2016) e demonstrado na decisão judicial mencionada nessa pesquisa ${ }^{15}$, é que há ainda uma forte influência da religião quando se trata da eutanásia. Os estudos têm demonstrado que a eutanásia ativa pode ser muito mais humanitária que a passiva em alguns casos, não havendo razões - exceto religiosas, que defendem uma visão de mundo ligada à santidade da vida - para proibir a concretização de algumas formas de eutanásia ativa. Somando-se tal fato à possibilidade de o paciente escolher de forma autônoma como deseja morrer, assegurando-lhe o direito a uma morte digna, como se tem comumente chamado, não há justificativa robusta para restrição da eutanásia ativa.

Assim, embora o projeto tenha o escopo de dirimir incertezas no campo jurídico, ele apenas as fomenta, ao regulamentar a matéria de forma superficial e ao não levar em conta que as distinções éticas e jurídicas entre as modalidades de eutanásia são duvidosas. Em que pese a inflexibilidade do ordenamento jurídico brasileiro atualmente em vigor, em um Estado Democrático de Direito os indivíduos não devem estar sujeitos a restrições de opções sobre como desejam lidar com a morte. A

\footnotetext{
14 Na eutanásia ativa direta o agente intencionalmente causa o resultado morte. Por sua vez, na eutanásia ativa indireta o dolo é eventual.

15 A decisão mencionada faz referência expressa à Encíclica Evangelium Vitae, editada pelo papa João Paulo II, em sua fundamentação (RIO GRANDE DO SUL, 2013).
} 
ortodoxia que limita de maneira intransigente o direito a dirigir antecipadamente os tratamentos de saúde, principalmente em condições de terminalidade, estado vegetativo ou sofrimento excessivo, tem diminuído e tem-se configurado, de maneira consistente, o direito de morrer, e de morrer bem. A obstinação terapêutica (distanásia) representa normalmente uma morte lenta e carregada de intenso padecimento físico e psicológico, não só para a vítima, mas também para todo o círculo próximo, de parentes e amigos.

Não há que se confundir a ideia de sacralidade da vida (vida humana tem valor especial e intrínseco) com a ideia de santidade da vida humana (de cunho dogmático e religioso), incabível do ponto de vista institucional no Estado laico. A tendência de envelhecimento populacional, associada ao vertiginoso avanço das tecnologias biomédicas intensifica a reflexão, necessária, sobre o direito à vida e à morte, bem como sobre as modalidades de eutanásia. O senso comum, a partir de uma revalorização e de uma ressignificação da autonomia, da dignidade e da liberdade do paciente tem rumado à inclusão da eutanásia como um direito fundamental.

A necessidade de dar uma solução adequada e eficiente a este problema passa pela compreensão de uma expressão pública de cuidado pela vida, um desafio diante da crescente medicalização da morte.

\section{REFERÊNCIAS}

BRASIL. Constituição Federal de 1988. Promulgada em 5 de outubro de 1988. Disponível em: https://bit.ly/3qsfHBF. Acesso em: 5 jun. 2019.

BRASIL. Decreto-Lei no 2.848, de 7 de dezembro de 1940. Código Penal Brasileiro. República Federativa do Brasil. Disponível em: https://bit.ly/2Jpnkbr. Acesso em: 11 abr. 2019.

BRASIL. Projeto de Lei do Senado $\mathbf{n}^{\circ} 149$ de 2018. Dispõe sobre as diretivas antecipadas de vontade sobre tratamentos de saúde. Disponível em: https://bit.ly/2VyNzOW. Acesso em: 5 jun. 2019.

BRASIL. Senado Federal. Projeto de Lei do Senado $\mathbf{n}^{\mathbf{0}}$ 6.715/2009. Altera o Decreto-Lei $\mathrm{n}^{\circ}$ 2.848, de 7 de dezembro de 1940 (Código Penal), para excluir a ilicitude da ortotanásia. Disponível em: https://bit.ly/37BpHQt. Acesso em: 5 jun. 2019.

BRASIL. Senado Federal. Projeto de Lei do Senado PLS n 236, de 2012. Reforma do Código Penal Brasileiro. Disponível em: https://bit.ly/2JvNKIg. Acesso em: 5 jun. 2019.

CAUDURO, Joseane. O conceito de eutanásia em Ronald Dworkin. 2007. Dissertação (Mestrado em Direito) - Universidade de Caxias do Sul, Caxias do Sul, 2007. Disponível em: https://bit.ly/3qjJZpY. Acesso em: 2 jul. 2019. 
CAVALHEIRO, Carmela Marcuzzo do Canto. A tolerância da eutanásia nos Países Baixos e o debate no Brasil: aspectos jurídicos. Revista Brasileira de Ciências Criminais, [s. l.], n. 126, p. 15-36, 2016.

CHRISTMAN, John. Autonomy in Moral and Political Philosophy. The Stanford Encyclopedia of Philosophy, [s. l.], Fall 2020 Edition, Edward N. Zalta (Ed.). Disponível em: https://stanford.io/39zuYum. Acesso em: 7 jul. 2020.

CONSELHO FEDERAL DE MEDICINA (CFM). Código de ética médica: Resolução CFM n ${ }^{\circ}$ 1.931, de 17 de setembro de 2009 (versão de bolso). Brasília: Conselho Federal de Medicina, 2010.

CONSELHO FEDERAL DE MEDICINA (CFM). Resolução no 1.805. Publicada no D.O.U., 28 nov. 2006, Seção I, p. 169. Brasília: Conselho Federal de Medicina, 2006. Disponível em: https://bit.ly/2VxhMOv. Acesso em: 2 jun. 2019.

CONSELHO FEDERAL DE MEDICINA (CFM). Resolução n 1.995. Publicada no D.O.U. de 31 de agosto de 2012, Seção I, p. 269-70. Brasília: Conselho Federal de Medicina, 2012. Disponível em: https://bit.ly/39BN0w0. Acesso em: 2 jun. 2019.

CONSELHO NACIONAL DE JUSTIÇA (CNJ). Enunciados aprovados na I Jornada de Direito da Saúde do Conselho Nacional de Justiça. 15 de maio de 2014. São Paulo-SP. Disponível em: https://bit.ly/33F8dS3. Acesso em: 2 jun. 2019.

DADALTO, Luciana. A judicialização do testamento vital: análise dos autos n. 108440521.2015.8.26.0100/TJSP. Civilistica.com - Revista Eletrônica de Direito Civil, [s. l.], v. 7, p. 1-16, 2018. Disponível em: https://bit.ly/3lE1TQT. Acesso em: 2 jun. 2019.

DADALTO, Luciana. História do Testamento Vital: entendendo o passado e refletindo sobre o presente. Mirabilia, [s. l.], v. 4, p. 23-41, 2015. Disponível em: https://bit.ly/37MNtJp. Acesso em: 4 jul. 2019.

DADALTO, Luciana; CARVALHO, Carla Vasconcelos. Em busca de um consenso jurídico acerca da limitação de hidratação e nutrição nos cuidados com o fim da vida. Instituto Brasileiro de Direito Civil, Rio de Janeiro, v. 10, n. 4, p. 28-43, 2016. Disponível em: https://bit.ly/39Ek5Y1. Acesso em: 2 jun. 2019.

DWORKIN, Gerald. Paternalism. The Stanford Encyclopedia of Philosophy, [s. l.], Summer 2020 Edition, Edward N. Zalta (Ed.). Disponível em: https://stanford.io/36GURXr. Acesso em: 7 jul. 2020.

FADEN, Ruth; BERNSTEIN, Justin; SHEBAYA, Sirine. Public Health Ethics. The Stanford Encyclopedia of Philosophy, [s. l.], Fall 2020 Edition, Edward N. Zalta (Ed.). Disponível em: https://stanford.io/33IWgKS. Acesso em: 7 jul. 2020.

FREITAS, R. S.; ZILIO, D. Os direitos da personalidade na busca pela dignidade de viver e de morrer: o direito à morte (digna) como corolário do direito à vida (digna). Revista de Direitos e Garantias Fundamentais, [s. l.], v. 17, p. 171-190, 2016. Disponível em: https://bit.ly/3g82U2r. Acesso em: 2 jun. 2019. 
FREITAS, Riva Sobrado de; BAEZ, Narciso Leandro Xavier. Privacidade e o direito de morrer com dignidade. Revista de Ciências Jurídicas Pensar, Fortaleza, v. 19, n. 1, p. 249-269, 2014. Disponível em: https://bit.ly/37y2q1B. Acesso em: 5 jul. 2019.

GARCIA, Iberê Anselmo. Aspectos médicos e jurídicos da eutanásia. Revista Brasileira de Ciências Criminais, [s. l.], v. 67, p. 253-275, 2007.

JAMIESON, Dale (Ed.). Singer and his critics. Malden, Massachussets: Blackwell, 2000.

OLIVEIRA, Diego Ferreira de. A morte com dignidade e a autonomia do indivíduo: uma discussão sobre a necessidade de regulamentação da ortotanásia no Brasil. 2016. Dissertação (Mestrado em Direito) - Universidade Federal do Maranhão, São Luís, 2016.

RACHELS, James. Active and passive euthanasia. New England Journal of Medicine, [s. l.], n. 292, p. 78-80, 1975.

RIO GRANDE DO SUL. Tribunal de Justiça do Rio Grande do Sul. Apelação Cível No 70054988266. Intervenção cirúrgica. Cirurgia. Realização. Paciente. Obrigatoriedade. Inexistência. Amputação. Biodireito: mesmo sob risco de vida, paciente não é obrigado a passar por cirurgia. Primeira Câmara Cível. Relator Irineu Mariani. Data do julgamento: 20.11.2013. Diário da Justiça, 27.11.2013. Disponível em: https://bit.ly/3qsOrTg. Acesso em: 5 jun. 2019.

SAMESHIMA, Marcelo Fonseca. A eutanásia no ordenamento jurídico-penal brasileiro. 2012. Monografia (Graduação em Direito) - Centro Universitário de Brasília, Brasília, 2012. Disponível em: https://bit.ly/3lGnfgi. Acesso em: 2 jul. 2019.

SANCHES, Vladia Maria de Moura Soares. O testamento vital e o princípio da dignidade da pessoa humana. Revista de Direito Constitucional e Internacional, [s. l.], v. 87, 2014.

SINGER, Peter. Ética Prática. Tradução Jefferson Luiz Camargo. 4. ed. São Paulo: Martins Fontes, 2018.

VARALLI, Janaina Thais Daniel. A morte digna, direito fundamental. 2017. Tese (Doutorado em Direito) - Pontifícia Universidade Católica de São Paulo, São Paulo, 2017. Disponível em: https://bit.ly/3olnZsX. Acesso em: 2 jul. 2019. 